University of Wollongong

Research Online

Faculty of Social Sciences - Papers (Archive) Faculty of Arts, Social Sciences \& Humanities

2015

Upper limb spasticity management for patients who have received Botulinum Toxin A injection: Australian therapy practice

Anne Cusick

University of Wollongong, acusick@uow.edu.au

Natasha Lannin

La Trobe University, N.Lannin@alfred.org.au

Bianca Kinnear

University of Wollongong, bzk222@uowmail.edu.au

Follow this and additional works at: https://ro.uow.edu.au/sspapers

Part of the Education Commons, and the Social and Behavioral Sciences Commons

Research Online is the open access institutional repository for the University of Wollongong. For further information contact the UOW Library: research-pubs@uow.edu.au 


\title{
Upper limb spasticity management for patients who have received Botulinum Toxin A injection: Australian therapy practice
}

\author{
Abstract \\ Background/aim To describe Australian physiotherapy and occupational therapy practice for patients who \\ receive upper-limb Botulinum Toxin-A (BoNT-A). Method Anonymous online survey asking about practice \\ experience. Convenience sample of 128 BoNT-A experienced occupational therapists and \\ physiotherapists. Results The primary work setting was multidisciplinary inpatient or outpatient \\ rehabilitation services where therapists had automatic referral to BoNT-A patients. Patients expected \\ BoNT-A to improve functional movement, reduce hypertonicity, increase passive range, reduce pain, \\ improve appearance and hand hygiene. Most patients were injected in multidisciplinary public hospital \\ clinics and had median 2 pre-injection (range 0-30) and 8 post-injection (range 0-50) therapy sessions. \\ Biceps, flexor digitorum profundus/superficialis and brachoradialis were most frequently injected. \\ Injectors used therapist assessment information to select sites $68 \%$ of the time; only $44 \%$ of services had \\ assessment protocols. Standardised therapy assessments examined motor performance, pain and \\ function in that order of frequency. The greater the awareness and perceived relevance of an assessment \\ the more often therapists used it. All therapists set goals, most collaboratively, and these mirrored patient \\ expectations. The most common treatments were stretch, task-specific functional training, strength \\ training and home programmes. Conclusion While trends in Australian assessment, goals and treatment \\ practice were observed, greater consistency could be achieved if therapy practice guidelines existed. The \\ gap is exacerbated by the absence of Australian BoNT-A organisation and process of care spasticity \\ management guidelines. This creates an environment where practice variability is inevitable. \\ Recommendations to improve local service quality are made.
}

\section{Keywords}

therapy, spasticity, australian, injection, toxin, botulinum, received, have, who, upper, limb, patients, practice, management

\section{Disciplines}

Education | Social and Behavioral Sciences

\section{Publication Details}

Cusick, A., Lannin, N. \& Kinnear, B. Z. (2015). Upper limb spasticity management for patients who have received Botulinum Toxin A injection: Australian therapy practice. Australian Occupational Therapy Journal, 62 (1), 27-40. 


\section{INTRODUCTION}

Upper limb spasticity is a common consequence of neurological events such as stroke. Spasticity is "a motor disorder characterized by a velocity-dependent increase in tonic stretch reflexes (muscle tone) with exaggerated tendon jerks, resulting from hyper excitability of the stretch reflex" (Lance,1980,p.485). It emerges over time (Lundström, Smits, Terént, \& Borg,2010), and can have devastating effects on quality of life through associated pain, limitations to passive and active movement, threats to skin integrity, difficulties in self-care and limb hygiene and in the long term, the potential for fixed contracture (Kong, Chua, \& Lee,2010; Stevenson,2010). Traditional occupational therapy and physiotherapy approaches to spasticity management have, more recently, been augmented by pharmacotherapy such as Botulinum toxin -A (BoNT-A) injections. BoNT-A has been demonstrated to be safe and effective in reducing focal spasticity in a range of neurological conditions (Delgado, Hirtz, Aisen et al.,2010; Muller, Cugy, Ducerf et al.,2012; Simpson, Gracies, Graham et al.,2008). In Australia, the National Stroke Foundation (NSF) does not recommend BoNT-A for everyone with spasticity, rather, for those patients who have persistent moderate to severe spasticity that "interferes with activity or personal care" (NSF,2010)(Guide 7.3b). BoNT-A injection for post-stroke upper limb spasticity in Australia is subsidized through the government Pharmaceutical Benefits Scheme (PBS) "S100 Botulinum Toxin Program criteria for availability". To be eligible a patient with upper limb post-stroke spasticity requires an:-

"MAS greater than or equal to 3 using modified Ashworth scale ... as second line therapy when standard management has failed ... or as an adjunct to physical therapy ... [BoNT-A] treatment should be discontinued if the patient does not respond (decrease of MAS greater than 1 in at least one joint) after two treatments" (Department of Human Services Australian Government, 2012).

Injection can only be done by a medical practitioner in Australia and this is usually a neurologist or rehabilitation physician. 
BoNT-A for spasticity management can be used in isolation but researchers and peak rehabilitation bodies recommend multidisciplinary organisation of services and processes for care (Ozcakir \& Sivrioglu,2007; Quinn, Paolucci, Sunnerhagen et al.,2009; Royal College of Physicians, British Society of Rehabilitation Medicine, Chartered Society of Physiotherapy, Association of Chartered Physiotherapists Interested in Neurology,2009; Sheean et al., 2010; Turner-Stokes \& Ward 2009; Wissel, Gracies, Graham et al.,2008). Multidisciplinary BoNT-A spasticity management processes of care should include the following elements: managing patient expectation, developing functional goals, using treatment plans and outcome measures, ensuring post-injection therapy review, implementing post-review treatment planning and providing self-management support (Allison \& Knapp,2012). To date little information about processes of care as evidenced by practice patterns is available (eg., Williams, Olver, De Graff, \& Singer,2012 is the only study to date on Australian therapy BoNT-A related practice); and as yet practice guidelines for BoNT-A related therapy assessment and treatment have not been developed (Levy, Giuffrida, Richards et al.,2007; Sun, Hsu, Sun et al.,2010; Weber, Skidmore, Niyonkuru et al.,2010). Evidence regarding post-stroke treatment effects in multidisciplinary spasticity management is also limited (Demetrios, Khan, Turner-Stokes, Brand \& McSweeney,2013). This study helps fill these evidence gaps by exploring BoNT-A related therapy practice in Australia, augmenting previous work (Williams et al., 2012), by extending enquiry into factors relating to the organisation and process of care including injection and therapy settings, referral arrangements, muscles injected, assessments used and goal setting. Background information relating to these factors is now briefly reviewed.

Muscles injected: Currently, there are no Australian BoNT-A spasticity management guidelines to inform physician injection decisions. The Australasian Faculty of Rehabilitation Medicine (AFRM)(2009a) has only one position statement relating to use of BoNT-A (AFRM,2009b); this dates back to 1997 and it is not specific to spasticity management in adults. Although international BoNT-A spasticity management guidelines are available, the AFRM does not appear to have appraised or 
endorsed them. Australian injectors therefore set their own BoNT-A spasticity management standards and determine their own processes for site selection and post-injection follow-up. Injector preference, not factors such as patient goals or severity of spasticity, have been shown to underpin BoNT-A muscle site selection in Australia (Baguely, Nott, Turner-Stokes et al.,2011).

Goals and Goal setting: Spasticity management should be goal directed and these goals should address function (NSF, 2010; Quinn et al.,2009; Royal College of Physicians et al,2009; Sheean et al.,2010; Turner-Stokes \& Ward,2009; Wissel et al.,2010). Goal-setting that involves patients, carers, therapists and physicians is also recommended (Allison \& Knapp,2012; Royal College of Physicians et al.,2009). Goal types can differ in frequency depending on spasticity recovery stage (Bakheit, Zakine, Maisonobe et al.,2010; Royal College of Physicians et al.,2009; Williams et al.,2012). In the early months of recovery the most common goal for BoNT-A treatment is active functional recovery, but in chronic spasticity management it is passive function. Pain relief is a common goal in both early and chronic spasticity conditions.

Assessments: Assessment should help inform goal setting and evaluation of goal attainment. Standardised functional assessments are however, rarely used in BoNT-A related therapy (Bakheit et al.,2010; Williams et al.,2012). Instead, one Australian study found goal achievement was measured through patient or family self-report, standardised outcome measures that may not reflect activities of daily living, or non-standardised assessments (Williams et al.,2012).

Treatment modalities: Therapy treatment for BoNT-A patients includes physical modalities (such as sustained stretch using serial casting, orthoses, taping/strapping), strengthening, forced use motor training (constraint-induced movement therapy), repetitive task specific practice and/or mental practice, "movement based therapy", home exercise programs, electrical stimulation to agonist and injected muscles, and adaptation of activities or the environment to prevent and minimize adverse impact of spasticity on function (Ada, Dorsch, \& Canning,2006; Demetrios et al.,2013; Katalinic, Harvey, Herbert et al.,2010; Page, Murray, \& Hermann,2011; Treger, Aidinof, Lehrer, \& Kalichman,2012; 
Williams et al.,2012). Currently there are no modality-specific guidelines for treatment type, frequency or duration, nor is much known about current practice. Evidence of multidisciplinary rehabilitation effect is considered limited in scope and of low quality (Demetrios et al.,2013). To date there has been debate about BoNT-A's contribution to attainment of functional goals (Caty, Detrembleur, Bleyenheuft et al.,2009; Cousins, Ward, Roffe et al.,2001; Delgado et al.,2010; Francis, Wade , Turner-Stokes et al.,2004; Galvin \& Sakzewski,2011; Lai, Francisco, \& Willis,2009; Patel,2011; Rosales, Kong, Goh et al.,2002). At the same time there has been promising evidence that BoNT-A plus therapy may have sustained positive effects in spasticity reduction (Katalinic et al.,2010; Wolf, Milton, Reiss et al.,2012) and functional outcomes (Ada et al.,2006; Page et al.,2011; Treger et al.,2012).

\section{METHODS}

This study aims to describe current Australian spasticity management practice by outlining the organisation and processes of care from a therapist perspective. To do this, an online anonymous selfreport survey was conducted with therapists who responded to a study invitation distributed through informal neuro-rehabilitation occupational therapy and physiotherapy networks in Australia. Recruitment took place after approval of researcher institutional research ethics committees. The study invitation specified that participants needed to be working in Australia, have upper limb neurological rehabilitation experience in the past five years, and experience working in services where patients had received BoNT-A injections.

The author-designed survey asked demographic and clinical experience questions. Organisation of BoNT-A care was explored through questions about: proportion of neuro-rehabilitation caseload that received BoNT-A, injection setting, referral process, patient access to therapy, therapy setting and service type. Processes of BoNT-A therapy care were examined by questions about: patient expectations; muscles injected; assessments used (rated as: not heard of it, never, rarely, sometimes, often, always); assessment relevance (rated as: don't know, essential must be included important, 
acceptable, marginal, not relevant shouldn't be included)(scale adapted from Clemson, Fitzgerald \& Heard,1999; Skakun \& King,1980); injector use of assessment information in site selection; whether or not the service had an assessment protocol; goal-setting; goals set (rated on: never, rarely, sometimes, often always); and treatment modalities used (rated on: never, rarely, sometimes, often, always). Even though BoNT-A cannot reduce contracture this was included in the goal questions because anecdotally it was reported to be in use.

Responses were submitted by participants into Survey Monkey ${ }^{\mathrm{TM}}$ and data was imported to SPSS Version 20 (IBM, 2011). A value was allocated to Likert-type responses (higher values to higher ratings; not heard of it and don't know reported separately); item values were summed and then ranked to show trends. Comments were invited regarding other goals and whether or not all patients who receive BoNT-A receive therapy. Comments with the same or similar wording were grouped together so the range of the responses could be reported. In the case of patient expectations, the number of responses in each category was tallied to show trends. No question in the survey was compulsory. Missing items are noted in the text or tables.

\section{RESULTS}

All participants ( $n=128$ ) were university qualified; aged between 23 and 60 years (mean 33.5; median 32; SD 7.8). They were predominantly female occupational therapy clinicians working in capital cities in inpatient or outpatient rehabilitation services (Table 1). Only $27.9 \%(n=33)$ worked some or all of the time in a BoNT-A clinic ( $n=85,72 \%$ did not; $n=10$ missing). Most had worked with 10 or less BoNT-A injection patients in their career and $10 \%$ or less of their neurology caseload were injected patients. Overall, participants ( $n=127$ ) had significant total career (mean 11.5, median 10, SD8.1, range 1.5 to 40 years) and neurology (mean 8.9, median 7, SD7.8, range 7 months to 35 years) clinical experience. For most of the $n=122$ respondents, years of BoNT-A experience were less than half that of their neurology experience (mean 4.12, median 3, SD3.26, range 3 months to 15 years). In the past 12 months, $91.4 \%$ 
had seen neurological patients who had received upper limb BoNT-A injections and 58.6\% had current BoNT-A patients.

Organisation of care

Overwhelmingly, BoNT-A injections were provided in public hospital BoNT-A spasticity management clinics (72\%), with half of the patients receiving injections in multidisciplinary services (49.5\%); a quarter were given in physician-only services (28.5\%)(Table 2). Most therapists (58.5\%) reported they could choose when they saw injected patients. Setting-specific automatic therapy referral known as "blanket referral" accounted for 23\% (Table2). Participants were asked whether they thought all patients who had received BoNT-A injections received therapy and most said "no" ( $n=68$ of 81 respondents; 84\%). Participants commented on issues they thought related to therapy access (Table 3); timely referral and team communication were important.

Process of care

Injections: Therapists reported most of their BoNT-A patients were 'first-time' BoNT-A recipients, (only $34 \%$ had repeat injections). Of 26 different upper limb muscles, participants reported that biceps, flexor digitorum profundus/ superficialis and brachoradialis were the most frequently injected (Table 4). Those muscles at the top of the 'never injected' list were in descending order, rhomboids, extensor digitorum, and extensor carpi ulnaris. The muscles most often 'not known' about by therapists were levator scapulae and subscapularis.

Assessments: Most participants reported their clinic/workplace did not have assessment protocol they had to use $(47.5 \%, n=61), 37 \%$ did $(n=48)(n=19,15 \%$ missing); but the overwhelming majority did assess their patients (all but 6 of 90 respondents; $n=38$ missing) before and after injection $(n=60,67 \%) .$. Most therapists thought physicians used their assessment findings always or sometimes to select injection sites ( $n=61,67.7 \%)$. Assessment awareness and frequency of use is presented in Table 5(footnote includes citations). All had heard of range of motion/goniometry, only one had not 
heard of the Modified Ashworth Scale or Ashworth Scale, two the manual muscle test, Barthel Scale and Motor Assessment Scale, and three the Goal Attainment Scale. The most frequently used assessments in order were range of motion (highest), next Modified Ashworth Scale, the Tardieu, Manual Muscle test, Modified Tardieu Scale, Motor Assessment Scale, the Pain Visual Analogue Scale, and then Goal Attainment Scaling. In general terms, greater use mirrored greater assessment awareness and perceived relevance.

Patient expectations: N=104 respondents described what they thought patients expected from their BoNT-A injection. In order from most to least frequent they were "active/functional movement/ dexterity" ( $n=43 ; 41.3 \%)$, improvement in hypertonicity/ tightness ( $n=19 ; 18.3 \%)$, increased passive range $(n=18,17.3 \%)$, reduction in pain $(n=16 ; 15.4 \%)$, enhanced appearance $(n=12,11.5 \%)$, and improved hygiene ( $n=9,8.6 \%)$.

Goals: Participants ( $n=83 ; 45$ missing) set goals either with $(97.6 \%, n=81)$ or independent of $(2.4 \%, n=2)$ patients and just over half of all patients had goals set before they were injected. There was a pattern in goal use: least used was increased upper limb dexterity, in increasing frequency was enhanced occupational therapy or physical therapy,enhanced cosmetic appearance of the upper limb, reduced contracture, increased upper limb active movement, reduced pain, and enhanced hygienic care was the most frequently used. $\mathrm{N}=47$ participants identified other goals: the most frequent one, "enhanced function", was usually qualified with the descriptor "task specific". Some participants gave examples of these tasks (eg., dressing) or indicated that tasks were identified by patients. Other goals were: (a) to enhance position or posture, upper limb movement patterns, repetitive reciprocal exercise, tolerance of and ability to wear orthoses, balance and gait safety and/or sleep through decreased pain; (b) maintain range of movement and/or joint integrity; (c) prevent contracture deterioration; and (d) decrease care-giver burden. 
Treatment modalities: Nine treatment modalities were rated from never to always used $(n=85$; 43 missing). In order from low to high use they were: biofeedback, orthotic casts, electrical stimulation/ functional electrical stimulation, orthotic splints, movement training, home programs, strength training, task specific functional training and stretch. Sixteen therapists reported they used other treatments (a) constraint induced movement therapy, (b) task and strength movement training, (c) weight bearing stretches, (d) therapeutic positioning, (e) general fitness program and (f) compensation training for functional activities

Treatment session frequency: Most patients were reported to receive pre-injection (mean 3.8, median 2, SD5.99, range 0 to 30 sessions; $n=18,24 \%$ had no pre-injection therapy) and postinjection sessions (mean 10.2, median 8, SD9.57, range 0 to $50 ; n=6,5.6 \%$ had no post-injection therapy). To calculate the number of therapy sessions the following decision rules were used because participants answered the question in a variety of ways. In the case of pre-injection therapy sessions: (a) $n=67$ participants gave a numerical estimate which was used; (b) $n=5$ gave a range and in this case the highest or the highest aggregate was used, eg. "1-6" was reported as 6 sessions while "1-6 weeks of 3-5 sessions/week" was reported as the function of 6 weeks by 5 sessions per week thus 30 sessions; (c) n=6 gave a weekly range eg., "3-5 per week", but because the number of weeks was not specified, a total could not be estimated so data was treated as missing;(d) n=31 gave no estimate but instead gave a description such as "variable/varies"=13, "daily"=5, "depends"=3, or some other word=10 such as "routine", "lots", "many", "several" and these were also treated as missing data; (e) $\mathrm{n}=19$ did not answer. Thus 56 of 128 pre-injection therapy responses were treated as missing data. In the case of post-injection therapy sessions the same 'rules' applied: (a) n=44 gave a numerical estimate; (b) n=25 gave a range; (c) n=9 gave a weekly range but did not specify number of weeks; (d) n=26 gave a descriptor instead of an estimate eg., "variable/varies"=5, "depends"=4;; (e) n=24 did not answer. Thus 59 of 128 post-therapy responses were treated as missing data.

\section{DISCUSSION}


At present Australian therapists must practice in the absence of national BoNT-A spasticity management guidelines and without therapy-specific guidelines in particular. This is a challenge given our findings that BoNT-A therapy was both exceptional and relatively new for most therapists. 'Exceptional' in that most therapists had seen few BoNT-A patients in their careers and the proportion of their caseload receiving BoNT-A was small. 'New' in that most therapists had BoNT-A years of experience that were less than half that of their neurology practice. The practice variability we observed may be a consequence of this infrequent and relatively new exposure. But equally it may result from varying local approaches to care developed without AFRM guidance regarding 'model' processes and organizational arrangements for multidisciplinary care. One participant comment illustrates current gaps:-

Most adult patients I have had experience with rarely see a therapist pre-injection. They also rarely receive post-injection therapy. If patients do have access to therapy services it is extremely uncommon that the therapist has the required skills to provide appropriate interventions such as casting, splinting and movement based interventions. The most significant issue is related to the model of service delivery for adults with a disability. Patient follow-up and monitoring over time is completely inadequate and patients are given their immediate post injection therapy and discharged. This is not appropriate for this patient population as their complex impairments need ongoing review and intervention Australian guidelines for BoNT-spasticity management and therapy specific guidelines are urgently required. Guidelines will provide a national benchmark for local practice improvement. Meanwhile therapists can improve their own process of care through professional development and consider implementing quality improvement activities to enhance local organization of care. The following recommendations provide a starting point for change.

This study demonstrated that most of the time, spasticity management was through multidisciplinary 'shared care' (NSF,2010; Wissel et al.,2008). But a minority reported this NSF recommendation was not implemented, with physicians injecting without referring to therapy, or the absence of a coordinated goal directed approach (Royal College of Physicians et al.,2009; Sheean et al.,2010). Multidisciplinary team communication, a feature of good quality care (NSF Guide 1.8) was also reported to be problematic in a minority of services, particularly in relation to physician-therapist- 
patient communication about patient expectations, functional goals, and injection site selection and follow up. The AFRM identifies a key function of rehabilitation physicians is to provide "coordinated and patient-focused program[s] of individual, goal directed rehabilitative care" (AFRM, 2009c). Team communication would appear to be central to achieving this. Local strategies targeting team communication could be implemented to help physicians fulfil the coordination function in relation to BoNT-A spasticity management.

There is promising evidence that BoNT-A plus therapy achieves positive results (Ada et al.,2006; Katalinic et al.,2010; Page et al.,2011; Treger et al.,2012; Wolf, Milton, Reiss et al.,2012), but participants reported that injected patients do not always receive therapy. Local strategies to encourage and streamline therapy referral should be developed. Service organization could be improved by providing sufficient therapy resources to meet demand of BoNT-A injected patients. If therapy cannot be provided, services need to consider whether funds spent on BoNT-A alone are a wise spasticity management investment.

Services also need to consider whether the timing and amount of therapy they provide is appropriate and adequate. The NSF Guide 6.1.1a (NSF, 2010) recommends as much practice as possible within the first six months of stroke, unfortunately our study did not examine when therapy occurred in relation to the stroke. NSF Guide 6.1.1b (NSF, 2010) recommends at least one hour therapy per day at least five days a week for patients in 'active rehabilitation'; unfortunately our study did not examine service arrangements for therapy sessions. But our study did obtain an estimate of the number of therapy sessions patients typically received which was pre-injection mean 3.8 (median 2) post-injection mean 10.2 (median 8) and a quarter of participants reported no pre or post therapy. Services should ensure that the number of pre- and post-injection therapy sessions, their timing in relation to the stroke event and their duration is monitored to help build an evidence base for future investigation. 
Processes of care could be improved at a local level through development of service protocols for referral, assessment, site selection, goal setting, treatment and follow-up. Timing and type of referral varied in this study; greater consistency could minimize barriers to patient access to therapy when it is available. Injector use of assessment findings also varied - some chose sites unrelated to assessment findings and goals. Service protocols that encourage a link between assessment findings, collaboratively developed functional goals (Royal College of Physicians et al.,2009; NSF Guide 1.4.2b ; Wissel et al.,2008; Turner-Stokes et al., 2009) and injection site selection would help facilitate a patient centered approach to spasticity management.

Processes of care could also be improved through professional development. Most services did not have assessment protocols and some participants did not use standardized assessments. While all participants set goals and most were functional, not all used functional assessments. The most frequently used assessments encompassed motor performance followed by pain and function. Greater use of standardized assessments, and functional assessments in particular would improve evidencebased decision-making and goal setting. Professional development may be required to enhance therapist knowledge of and skill in standardized functional assessment selection, administration and interpretation. This could be supported by service adoption of assessment protocols. One assessment illustrates the urgent need for professional development in assessment knowledge and skill. When compared with Williams et al. (2012) our sample had better uptake of the MAS, as only $45.7 \%$ of their sample used it. But given the critical role of the MAS as a threshold measure for PBS subsidy it would be expected that $100 \%$ of therapists should have used it and this was not the case. Australian therapists have previously reported their BoNT-A training was ad-hoc, gained through "lecture, seminar or workshop [attendance] related to Botulinum toxin injections and spasticity management" (Williams et al., 2012, p.259). This further reinforces the need for targeted professional development.

Processes of care could also be improved by services developing local treatment protocols and professional development to enhance therapist capacity in administering treatment modalities. The 
most common interventions in this study were recommended modalities: stretch (Demetrios et al.,2013), strength training (Guide 6.2.2), movement training and task-specific functional training (Guide 6.3.5a and b; Guide 6.4b), but consistency in approach is lacking without therapy guidelines. Local treatment protocols may fill that gap. Home programs were also common but as a modality they are opaque: services need to make explicit what is in them, frequency, duration and intensity particularly in relation to NSF Guides 6.1.1e and 6.3.5a that relate to practice. Services can also describe why some recommended treatments are not used. CMIT, for example is supported by the NSF Guide 6.3.5a, but barriers to use have been identified (Viana \& Teasell, 2012).

Limitations: This study was limited by the self-report, anonymous and convenience sampling design. The survey itself brought limitations because it was not standardized and subsequent analysis of results has revealed gaps and problems in data coding that weaken the study. While all therapists provided demographic and most provided clinical setting responses, there were many missing responses - especially at the point in the survey where participants were asked to use Likert-type scales to rate multiple items. Between a quarter and a third of participants did not respond to ratings even though all participants continued "clicking through" survey pages so they could submit. Response drop may have been due to responder fatigue, time pressures, or questions could have been difficult to answer if participants were not aware of organization of services at their workplace, or if they or their service did not know about or use the range of assessments, goals and treatments identified.

In conclusion, although BoNT-A therapy practice varies in Australia, trends were evident. On the whole, if patients are referred for therapy, most will have a multidisciplinary team providing coordinated care in a publicly funded inpatient or outpatient rehabilitation setting. Patients will have treatment goals set collaboratively, and these will reflect patient expectations and will focus on function. Standardized assessments will normally be used and assessments will collect information about patient motor performance, pain and function. Most patients will have home programs, but we don't know what these entail. Patients will receive therapy treatments that are generally consistent with NSF 
recommendations; however interventions lack strong evidence of effect. On the whole patients will receive more therapy sessions after injection than before, but more research is needed regarding session timing, frequency and duration. Development of Australian spasticity management guidelines or endorsement of international guidelines by peak professional bodies will provide a useful national benchmark for practice. Therapy guidelines can then be developed in a context where standards for organisation and processes of spasticity care are clear. 


\section{References}

Ada, L., Dorsch, S., \& Canning, C.G. (2006). Strengthening interventions increase strength and improve activity after stroke: a systematic review. Aust J Physiother, 52, 241-248. Retrieved from: http://www.ncbi.nlm.nih.gov/pubmed/17132118

Allison, R. \& Knapp, K.M. (2012). Spasticity management with botulinum toxin: development and evaluation of a tool for audit. J Rehabil Med,44, 558-561. doi: 10.2340/16501977-0977

Australasian Faculty of Rehabilitation Medicine, (2009a). The Royal Australasian College of Physicians -Home Page. Retrieved from http://www.racp.edu.au/page/racp-faculties/australasian-faculty-ofrehabilitation-medicine

Australasian Faculty of Rehabilitation Medicine, (2009b). Consensus statement BOTULINUM TOXIN (1997) - UNDER REVIEW. Retrieved from http://www.racp.edu.au/index.cfm?objectid=02A28582E795-54CF-2A8041E0BD658E1E

Australasian Faculty of Rehabilitation Medicine, (2009c). Position Statement Rehabilitation Medicine Scope of Practice (Adult Rehabilitation Medicine) (2011). Retrieved from http://www.racp.edu.au/index.cfm?objectid=02A28582-E795-54CF-2A8041E0BD658E1E

Baguely, I.J., Nott, M.T., Turner-Stokes, L., De Graaff, S., Katrak, P., McCrory, P.et al. (2011). Investigating muscle selection for botulinum toxin-A injections in adults with post-stroke upper limb spasticity. J Rehabil Med, 1032-1037. doi: 10.2340/16501977-0885

Bakheit, A.M., Zakine, B., Maisonobe, P., Aymard, C., Fhedoroff, K., Hefter, H. et al. (2010). The profile of patients and current practice of treatment of upper limb muscle spasticity with botulinum toxin type A: an international survey. Int Rehabil Rehab Res, 33, 199-204. doi: 10.1097/MRR.0b013e328332f5e0

Caty, G.D., Detrembleur, C., Bleyenheuft, C., Deltombe, T., \& Lejeune, T.M. (2009). Effect of Upper Limb Botulinum Toxin Injections on Impairment, Activity, Participation, and Quality of Life Among Stroke Patients. Stroke, 40, 2589-2591. doi: 10.1161/STROKEAHA.108.544346

Clemson, L., Fitzgerald M., \& Heard, R. (1999).Content validity of an assessment tool to identify home fall hazards: The Westmead Home Safety Assessment. British Journal of Occupational Therapy, 62, 171-179.

Cousins, E., Ward, A., Roffe, C., Rimington, L., \& Pandyan, A. (2001). Does low-dose botulinum toxin help the recovery of arm function when given early after stroke? A phase II randomized controlled pilot study to estimate effect size. Clin Rehabil, 24, 501-513. doi: 10.1177/0269215509358945

Delgado, M.R., Hirtz, D., Aisen, M., Ashwal, S., Fehlings, D.L., McLaughlin, J. et al. (2010). Practice Parameter: Pharmacologic treatment of spasticity in children and adolescents with cerebral palsy (an evidence-based review): Report of the Quality Standards Subcommittee of the American Academy of Neurology and the Practice Committee of the Child Neurology Society. Neurology, 74, 336-343. doi: 10.1212/WNL.0b013e3181cbcd2f

Demetrios, M., Khan, F., Turner-Stokes L., Brand C.,\& McSweeney S. (2013). Multidisciplinary rehabilitation programmes following treatment of spasticity after stroke. Cochrane Review.

DOI: 10.1002/14651858.CD009689.pub2 
Department of Human Services Australian Government, (2012). Botulinum toxin.Retrieved from http://www.pbs.gov.au/medicine/item/6103F.

Francis, H.P., Wade, D.T., Turner-Stokes, L., Kingswell, R.S., Dott, C.S.,\& Coxon, E.A. (2004). Does reducing spasticity translate into functional benefit? An exploratory meta-analysis. J Neurol Neurosurg Psychiatry, 75, 1547-1551. Retrieved from: http://www.ncbi.nlm.nih.gov/pubmed/15489384

French, B., Thomas, L., Leathley, M., Sutton, C., McAdam, J., Forster, A. et al. (2010). Does repetitive task training improve functional activity after stroke? A Cochrane systematic review and meta-analysis. Journal of Rehab Medicine, 42, 9-14. doi: 10.2340/16501977-0473

Galvin, J. \& Sakzewski, L. (2011). Botulinum toxin A in conjunction with occupational therapy reduces spasticity and improves upper limb function and goal attainment in children with cerebral palsy. Aust Occup Ther J, 58, 132-133. doi: 10.1111/j.1440-1630.2011.00925.x

IBM Corp, (2011). IBM SPSS Statistics for Windows, Version 20.0. Armonk, NY: IBM CorplBM Corp. Released 2011.

Kaňovský, P., Slawek, J., Denes, Z., Platz, T., Comes, G., Grafe, S. et al. (2011). Efficacy and safety of treatment with Incobotulinum toxin A (botulinum neurotoxin type A free from complexing proteins; NT 201) in post-stroke upper limb spasticity. J Rehabil Med, 43, 486-492. doi: 10.2340/16501977-0796

Katalinic, O.M., Harvey, L.A., Herbert, R.D., Mosely, A.M., Lannin, N.A., \& Schurr, K. (2010). Stretch for the treatment and prevention of contractures. Cochrane Database of Systematic Reviews 2010. Retrieved from http://onlinelibrary.wiley.com/doi/10.1002/14651858.CD007455.pub2/abstract,jsessionid=1570E3F 408A1458B45C29321C1B660EB.d03t04

Kong, K.H., Chua, K.S., \& Lee, J. (2010). Symptomatic upper limb spasticity in patients with chronic stroke attending a rehabilitation clinic: Frequency, clinical correlates and predictors. J Rehabil Med, 42, 453-457. doi: 10.2340/16501977-0545

Lai, J.M., Francisco, G.E., \& Willis, F.B. (2009). Dynamic splinting after treatment with botulinum toxin type-A: a randomized controlled pilot study. Adv Ther, 26,241-248. doi: 10.1007/s12325-008-0139-2

Lance JW (1980). Symposium synopsis. In Spasticity: Disordered Motor Control. Edited by Feldman RG, Young RR, Koella WP. pp. 485-494 Miami: Symposia Specialists.

Levy, C.E., Giuffrida, C., Richards, L., Wu, S., Davis, S., \& Nadeau, S.E. (2007). Botulinum toxin a, evidence based exercise therapy, and constraint induced movement therapy for upper limb hemiparesis attributable to stroke: a preliminary study. Am J Phys Med Rehabil, 86, 696-706. Retrieved from: http://www.ncbi.nlm.nih.gov/pubmed/17709993

Lundström, E., Smits, A., Terént, A., \& Borg, J. (2010). Time-course and determinants of spasticity during the first six months following first-ever stroke. J Rehabil Med, 42, 296-301. doi:

10.2340/16501977-0509 
Muller, F., Cugy, E., Ducerf, C., Dellici, C., Guehl, D., Joseph, A. et al. (2012). Safety and self-reported efficacy of botulinum toxin for adult spasticity in current clinical practice: a prospective observational study. Clin Rehabil, 26,174-179. doi: 10.1177/0269215511412799

National Stroke Foundation. (2010). Clinical Guidelines for Stroke Management 2010 Retrieved from http://www.strokefoundation.com.au

Ozcakir, S. \& Sivrioglu, K. (2007). Botulinum Toxin in Poststroke Spasticity. Clin Med Res, 5, $132-$ 138. doi: $10.3121 / \mathrm{cmr} .2007 .716$

Page, S.J., Murray, C., \& Hermann, V. (2011). Affected upper-extremity movement ability is retained 3 months after modified constraint-induced therapy. Am J Occup Ther, 65, 589-593. Retrieved from: http://www.ncbi.nlm.nih.gov/pubmed/22026327

Patel, A.T. (2011). Successful treatment of long term, post-stroke upper limb spasticity with onabotulinum toxin A. PhysTher, 91,1636-1641. doi: 10.2522/ptj.20100370

Quinn, T.J., Paolucci, S., Sunnerhagen, K.S., Sivenius, J., Walker, M.F., Toni, D. et al. (2009). Evidence-based stroke rehabilitation: an expanded guidance document from the european stroke organisation (ESO) guidelines for management of ischaemic stroke and transient ischaemic attack 2008. J Rehabil Med, 41, 99-111. doi: 10.2340/16501977-0301

Rosales, R.L., Kong, K.H., Goh, K.J., Kumthornthip, W., Mok, V.C.T., Delgado-De Los Santos, M.M. et al. (2012). Botulinum Toxin Injection for Hypertonicity of the Upper Extremity Within 12 Weeks After Stroke: A Randomized Controlled Trial. Neurorehabil Neural Repair, 26, 812-821.

Royal College of Physicians, British Society of Rehabilitation Medicine, Chartered Society of Physiotherapy, Association of Chartered Physiotherapists Interested in Neurology. (2009). Spasticity in adults: management using botulinum toxin: national guidelines London, RCP. Retrieved from http://www.rcplondon.ac.uk/sites/default/files/documents/spasticity-in-adults-managementbotulinum-toxin.pdf

Sheean, G., Lannin, N.A., Turner-Stokes, L., Rawicki, B. \& Snow, B.J. (2010). Cerebral Palsy Institute. Botulinum toxin assessment, intervention and after-care for upper-limb hypertonicity in adults: international consensus statement. Eur J Neurol, 17, 74-93. doi: 10.1177/1545968311430824

Simpson, M.D., Gracies, J.M., Graham, H.K., Miyasaki, J.M., Naumann, M., Russman, B. et al. (2008).Assessment: Botulinum neurotoxin for the treatment of spasticity (an evidence-based review): Report of the Therapeutics and Technology Assessment Subcommittee of the American Academy of Neurology. Neurology, 70, 1691-1698. doi: 10.1212/01.wnl.0000311391.00944.c4

Skakun, E.N. \& King, S. (1980). A comparison of several score cutting procedures and their effects on success rates. Conference on Research in Medical Education, 19, 9-14.

Stevenson, V.L. (2010). Rehabilitation in practice: Spasticity management. Clin Rehabil, 24,293304. doi: 10.1177/0269215509353254

Sun, S.F., Hsu, C.W., Sun, H.P., Hwang, C.W., Yang, C.L., \& Wang, J.L. (2010). Combined Botulinum Toxin Type A with constraint induced movement therapy for chronic stroke patients with upper extremity 
spasticity: a randomized controlled study. Neurorehabil Neural Repair, 24,34-41. doi: $10.1177 / 1545968309341060$

Treger, I., Aidinof, L., Lehrer, H., \& Kalichman, L. (2012). Modified constraint-induced movement therapy improved upper limb function in subacute poststroke patients: a small-scale clinical trial. Top Stroke Rehabil, 19, 287-93. doi: 10.1310/tsr1904-287

Turner-Stokes, L. \& Ward, A.B. (2009). Guidelines for the use of Botulinum Toxin in the management of spasticity in adults: Concise Guidance to good practice. Royal College of Physicians, London.

Turner-Stokes, L., Baguley, I.J., De Graaff, S., Katrak, P., Sandanam, J., Davies, L. et al. (2009). Botulinum toxin A for treatment of upper limb spasticity following stroke: A multi-centre randomized placebo-controlled study of the effects on quality of life and other person-centred outcomes. J Rehabil Med, 41, 536-544. doi: 10.2340/16501977-0366

Viana, R. \& Teasell, R. (2012). Barriers to the implementation of constraint-induced movement therapy into practice. Top Stroke Rehabil., 19, 104-14. doi: 10.1310/tsr1902-104

Weber, D.J., Skidmore, E.R., Niyonkuru, C., Chang, C., Huber, L.M. \& Munin, M.C. (2010). Cyclic functional electrical stimulation does not enhance gains in hand grasp function when used as an adjunct to onabotulinumtoxinA and task practice therapy: a single blind, randomized controlled pilot study. Arch Phys Med Rehabil, 91, 679-686. doi: 10.1016/j.apmr.2010.01.010

Williams, G., Olver, J., De Graff, S., \& Singer, B.J. (2012). The use of Botulinum toxin Type A in the management of adult-onset focal spasticity: a survey of Australian Allied health professionals. Aust Occup Ther J, 59, 257-264. doi: 10.1111/j.1440-1630.2012.01027.x

Wissel, J., Ward, A.B., Erztgaard, P., Bensmail, D., Hecht, M.J., Lejeune, T.M. et al. (2008) European consensus table on the use of botulinum toxin type $A$ in adult spasticity. J Rehabil Med, 41,13-25. doi: 10.2340/16501977-0303

Wolf, S.L., Milton, S.B., Reiss, A., Easley, K.A., Shenvi, N.V., \& Clark, P.C. (2012). Further Assessment to Determine the Additive Effect of Botulinum Toxin Type A on an Upper Extremity Exercise Program to Enhance Function Among Individuals With Chronic Stroke but Extensor Capability , Arch PhysMed Rehabil. 93, 578-587. doi: 10.1016/j.apmr.2011.10.026 
Table 1: Demographic Data

\begin{tabular}{|c|c|c|c|}
\hline $\begin{array}{l}\text { Factor } \\
\text { ( } \mathrm{n} \text { of } 128 \text { respondents } \\
\text { who answered } \\
\text { question) }\end{array}$ & Categories & $\mathbf{n}$ & $\begin{array}{l}\text { \% of } \\
\text { respondents }\end{array}$ \\
\hline $\begin{array}{l}\text { Profession } \\
(n=126)\end{array}$ & $\begin{array}{l}\text { Physiotherapist } \\
\text { Occupational Therapist }\end{array}$ & $\begin{array}{l}50 \\
76\end{array}$ & $\begin{array}{l}39.7 \\
60.3\end{array}$ \\
\hline Gender(n=127) & Female & 114 & 90 \\
\hline $\begin{array}{l}\text { State or Territory } \\
\text { (All Australian } \\
\text { jurisdictions listed) } \\
(\mathrm{n}=128)\end{array}$ & $\begin{array}{l}\text { Australian Capital Territory } \\
\text { New South Wales } \\
\text { Northern Territory } \\
\text { Queensland } \\
\text { South Australia } \\
\text { Tasmania } \\
\text { Victoria } \\
\text { Western Australia }\end{array}$ & $\begin{array}{c}1 \\
43 \\
0 \\
10 \\
7 \\
11 \\
45 \\
11\end{array}$ & $\begin{array}{c}1 \\
33.5 \\
0 \\
8 \\
5.5 \\
8.5 \\
35 \\
8.5\end{array}$ \\
\hline $\begin{array}{l}\text { Geographical Location } \\
\text { of Current Work Setting } \\
(n=114)\end{array}$ & $\begin{array}{l}\text { Capital City } \\
\text { Other metropolitan area } \\
\text { Rural } \\
\text { Remote }\end{array}$ & $\begin{array}{c}92 \\
15 \\
7 \\
0\end{array}$ & $\begin{array}{c}81 \\
13 \\
6 \\
0\end{array}$ \\
\hline $\begin{array}{l}\text { Primary Work Role } \\
(n=128)\end{array}$ & $\begin{array}{l}\text { Clinician } \\
\text { Manager } \\
\text { Academic } \\
\text { Consultant } \\
\text { Researcher }\end{array}$ & $\begin{array}{c}110 \\
8 \\
4 \\
3 \\
3\end{array}$ & $\begin{array}{c}86 \\
6.5 \\
3 \\
2 \\
2\end{array}$ \\
\hline $\begin{array}{l}\text { Primary setting of } \\
\text { current Practice } \\
(n=119)\end{array}$ & $\begin{array}{l}\text { Intensive care unit } \\
\text { Acute hospital inpatient ward } \\
\text { Inpatient rehabilitation service } \\
\text { Outpatient rehabilitation service } \\
\text { Community rehabilitation service } \\
\text { Day Hospital } \\
\text { Private Practice } \\
\text { University clinical research } \\
\text { Spasticity Clinic (in or outpatient not } \\
\text { specified) } \\
\text { Both in and outpatient service }\end{array}$ & $\begin{array}{c}0 \\
10 \\
41 \\
35 \\
22 \\
4 \\
3 \\
2 \\
1 \\
1\end{array}$ & $\begin{array}{c}0 \\
8.5 \\
34.5 \\
29.5 \\
18.5 \\
3.5 \\
2.5 \\
2 \\
1 \\
1\end{array}$ \\
\hline $\begin{array}{l}\text { Number of BoNT-A } \\
\text { patients worked with in } \\
\text { career } \\
(n=128)\end{array}$ & $\begin{array}{l}<5 \\
5-10 \\
11-20 \\
21-30 \\
>30\end{array}$ & $\begin{array}{l}36 \\
37 \\
21 \\
11 \\
25\end{array}$ & $\begin{array}{c}28 \\
29 \\
16.5 \\
8.5 \\
19.5\end{array}$ \\
\hline $\begin{array}{l}\text { Patients in neurology } \\
\text { caseload who received } \\
\text { BoNT-A injection } \\
(n=109)\end{array}$ & $\begin{array}{l}<1 \\
1 \text { to }<5 \% \\
5 \% \\
<10 \% \\
10 \% \\
2025 \% \\
30 \% \\
40 \%\end{array}$ & $\begin{array}{c}6 \\
26 \\
23 \\
6 \\
22 \\
11 \\
5 \\
1\end{array}$ & $\begin{array}{c}5.5 \\
24 \\
21 \\
5.5 \\
20 \\
10 \\
4.5 \\
1\end{array}$ \\
\hline
\end{tabular}




\begin{tabular}{|l|l|c|c|}
\hline & $70 \%$ & 2 & 2 \\
& $95 \%$ & 2 & 2 \\
& N/A 2 & 2 & 2 \\
& Comment made no \% estimate given & 3 & 2.5 \\
\hline
\end{tabular}


Table 2: Organisation and process of care

\begin{tabular}{|c|c|c|c|}
\hline $\begin{array}{l}\text { Factor } \\
\text { (n of } 128 \text { participants } \\
\text { responding) }\end{array}$ & Category & $n$ & $\begin{array}{c}\text { \% of } \\
\text { respondents }\end{array}$ \\
\hline $\begin{array}{l}\text { Setting: Service type for } \\
\text { injection } \\
(n=128)\end{array}$ & $\begin{array}{l}\text { BoNT-A spasticity Clinic - public hospital } \\
\text { BoNT-A spasticity Clinic- private hospital } \\
\text { BoNT-A spasticity Clinic - private community } \\
\text { service (not hospital) } \\
\text { Public hospital doctor - not in a BoNT-A } \\
\text { clinic } \\
\text { Private hospital doctor - not in a BoNT-A } \\
\text { clinic } \\
\text { Private provider - not in a BoNT-A clinic } \\
\text { Other (Department Veterans Affairs } \\
\text { provider; mixed private public) }\end{array}$ & $\begin{array}{c}92 \\
2 \\
1 \\
24 \\
5\end{array}$ & $\begin{array}{c}72 \\
1 \\
1 \\
20 \\
4 \\
1 \\
1\end{array}$ \\
\hline $\begin{array}{l}\text { Setting: Percentage of } \\
\text { patients who received } \\
\text { their injection in a } \\
\text { multidisciplinary clinic } \\
\text { situation (ie injecting } \\
\text { doctor and OT/Physio) } \\
\text { (n=107) }\end{array}$ & $\begin{array}{l}\text { Zero } \\
<1 \\
1 \text { to } 5 \% \\
10 \% \\
20 \text { to } 25 \% \\
30 \% \\
50 \% \\
70-75 \% \\
80-85 \% \\
90-95 \% \\
100 \% \\
\text { Don't know } \\
\text { Not Applicable } \\
\text { Student Clinic }\end{array}$ & $\begin{array}{c}25 \\
1 \\
3 \\
3 \\
4 \\
4 \\
8 \\
3 \\
8 \\
15 \\
30 \\
1 \\
1 \\
1\end{array}$ & $\begin{array}{c}23 \\
1 \\
3 \\
3 \\
3.5 \\
3.5 \\
7.5 \\
3 \\
7.5 \\
14 \\
28 \\
1 \\
1 \\
1\end{array}$ \\
\hline $\begin{array}{l}\text { Service: Percentage of } \\
\text { patients who only see a } \\
\text { private } \\
\text { consultant/doctor at } \\
\text { the time of injection } \\
(n=106)\end{array}$ & $\begin{array}{l}\text { Zero } \\
<1 \text { to } 1 \% \\
5 \% \\
10 \text { to } 15 \% \\
20 \% \\
30 \text { to } 40 \% \\
50 \text { to } 60 \% \\
70 \text { to } 75 \% \\
80 \% \\
90 \text { to } 95 \% \\
100 \% \\
\text { Don't know } \\
\text { Not applicable }\end{array}$ & $\begin{array}{c}35 \\
2 \\
6 \\
12 \\
7 \\
2 \\
6 \\
5 \\
3 \\
6 \\
16 \\
5 \\
1\end{array}$ & $\begin{array}{c}33 \\
2 \\
5.5 \\
11 \\
6.5 \\
2 \\
5.5 \\
5 \\
3 \\
5.5 \\
15 \\
5 \\
1\end{array}$ \\
\hline $\begin{array}{l}\text { Service: Timing of } \\
\text { physician referral to } \\
\text { therapy } \\
(n=85)\end{array}$ & $\begin{array}{l}\text { "Blanket" referral (anytime) } \\
\text { Sometimes before injection } \\
\text { Sometimes after injection } \\
\text { Sometimes before or after - no pattern } \\
\text { Usually before injection } \\
\text { Usually after injection }\end{array}$ & $\begin{array}{c}19 \\
5 \\
8 \\
10 \\
3 \\
2\end{array}$ & $\begin{array}{c}23 \\
6 \\
9.5 \\
12 \\
3.5 \\
2.5\end{array}$ \\
\hline
\end{tabular}




\begin{tabular}{|l|l|c|c|}
\hline & Usually before or after - no pattern & 30 & 35.5 \\
& No referral for treatment & 8 & 9.5 \\
\hline Service: Timing of & Usually before injection only & 5 & 5.5 \\
therapy assessment in & Usually after injection only & 6 & 7 \\
relation to injection & Usually Before and after injection & 60 & 67.5 \\
(n=90) & Only sometimes & 13 & 14.5 \\
& Never & 6 & 5.5 \\
\hline Service: Physician use & Yes always & 30 & 33.3 \\
of therapy assessment & Yes sometimes & 31 & 34.4 \\
findings to decide & Rarely & 17 & 18.9 \\
where to inject & Never & 6 & 6.7 \\
(n=90) & Don't know & 6 & 6.7 \\
\hline Service: Timing of & With patients before injection & 56 & 68.5 \\
therapy goals setting in & With patients after injection & 9 & 11 \\
relation to injection & With patients but in no particular pattern & 16 & 18 \\
(n=83) & Without patients before injection & 2 & 2.5 \\
& Without patients after injection & 0 & 0 \\
& I do not set goals & 0 & 0 \\
\hline Service: Percentage of & Zero & 7 & 8 \\
BoNT-A therapy & $<5$ to 5\% & 8 & 9 \\
patients who have pre- & 20 to 25\% & 4 & 4.5 \\
injection goal setting & 30 to 40\% & 2 & 2 \\
for & $50 \%$ & 5 & 6 \\
(n=86) & 60 to 65\% & 2 & 2.5 \\
& 70 to 75\%\% & 11 & 13 \\
& $80 \%$ & 10 & 11.5 \\
& 90 to 95\% & 7 & 8 \\
& 99 to 100\% & 1 & 34 \\
\hline & Not applicable & 1 \\
\hline
\end{tabular}


Table 3: Issues related to therapy access

\begin{tabular}{|c|c|c|}
\hline Issue & Example & Participant comment \\
\hline \multirow{5}{*}{$\begin{array}{l}\text { Shared care } \\
\text { not } \\
\text { implemented }\end{array}$} & $\begin{array}{l}\text { Physicians inject without referring } \\
\text { to therapy }\end{array}$ & $\begin{array}{l}\text { Some doctors injecting in private room or individual consults do not } \\
\text { refer on }\end{array}$ \\
\hline & $\begin{array}{l}\text { Physicians inject and refer to } \\
\text { therapy after }\end{array}$ & $\begin{array}{l}\text { I often get client[s] referred to me after injections have been done by } \\
\text { a private doctor, where by no client goal setting has been done. }\end{array}$ \\
\hline & $\begin{array}{l}\text { Physicians inject without } \\
\text { consulting team }\end{array}$ & $\begin{array}{l}\text { At times the Dr's have been known to inject pt's [sic] on our wards } \\
\text { with NIL communication with allied health staff. }\end{array}$ \\
\hline & $\begin{array}{l}\text { Physician beliefs about utility of } \\
\text { therapy }\end{array}$ & $\begin{array}{l}\text { I do not believe our Dr's feel that injected pt's [sic] need intensive } \\
\text { therapy to get results, and that is a massive barrier. At times Dr's } \\
\text { have injected different muscles to those recommended by OT/PT - } \\
\text { we are not always present at injection clinics }\end{array}$ \\
\hline & Patient beliefs and expectations & $\begin{array}{l}\text { It can be viewed by the patient and family, as a quick fix. Not } \\
\text { something which may need intense therapy and home programs to } \\
\text { gain the full benefit from }\end{array}$ \\
\hline \multirow{4}{*}{$\begin{array}{l}\text { Post- } \\
\text { injection } \\
\text { therapy not } \\
\text { available } \\
\text { patients }\end{array}$} & $\begin{array}{l}\text { Injections occur in city; patients } \\
\text { live in regional areas }\end{array}$ & $\begin{array}{l}\text { Some patients in regional areas also receive injections whilst in } \\
\text { Sydney then return to regional area and do not receive follow up }\end{array}$ \\
\hline & $\begin{array}{l}\text { Injections occur in city and } \\
\text { patients live in rural areas }\end{array}$ & $\begin{array}{l}\text { If patients don't live locally, can be ... a challenge when many of our } \\
\text { patients live out of area or in rural areas }\end{array}$ \\
\hline & $\begin{array}{l}\text { Discharge care destinations may } \\
\text { not have therapy }\end{array}$ & $\begin{array}{l}\text { Some are nursing home residents with limited access to therapy } \\
\text { They may not be in a facility that has PT and OT }\end{array}$ \\
\hline & $\begin{array}{l}\text { Patients cannot access therapy } \\
\text { centre }\end{array}$ & $\begin{array}{l}\text { Some clients don't come into the centre due to access to the centre. } \\
\text { We do not provide transport unless they cannot make it in with other } \\
\text { means }\end{array}$ \\
\hline \multirow{6}{*}{$\begin{array}{l}\text { Therapy staff } \\
\text { inadequate } \\
\text { for demand }\end{array}$} & Waiting lists & Sometimes a delay in getting them booked in due to availability \\
\hline & Short-staffed & PT/OT could be short-staffed \\
\hline & Competing demands & $\begin{array}{l}\text { Level of therapy may not be ideal in some situations secondary to } \\
\text { staffing difficulties within an acute setting }\end{array}$ \\
\hline & BoNT-A therapy unavailable & $\begin{array}{l}\text { These [therapy services] are quite sparse and I doubt they receive } \\
\text { the intensity they should }\end{array}$ \\
\hline & No funding for therapy & In our District we currently have no funding for allied health \\
\hline & Patient prioritizing & $\begin{array}{l}\text { We are getting to the stage where we would never be able to see } \\
\text { any other clients if we continued to see the BoNT-A clients forever. } \\
\text { So we are deciding who benefits from [follow-up] treatment by } \\
\text { looking at newly referred clients in assessment sessions preBoNT-A. }\end{array}$ \\
\hline \multirow{3}{*}{$\begin{array}{l}\text { Coordinated } \\
\text { goal directed } \\
\text { care not } \\
\text { implemented }\end{array}$} & $\begin{array}{l}\text { BoNT-A injection needs } \\
\text { coordinated follow-up }\end{array}$ & $\begin{array}{l}\text { BoNT-A without follow up (at least advice) is a waste of time for UL } \\
\text { unless it is something really simple like pain relief - which it rarely is }\end{array}$ \\
\hline & $\begin{array}{l}\text { Goal directed multidisciplinary care } \\
\text { impeded }\end{array}$ & $\begin{array}{l}\text { Rehab consultant ... He does not include allied health prior to or } \\
\text { during BoNT-A injections so we never get to look at the patient from } \\
\text { a team perspective to see ... what the goals might be }\end{array}$ \\
\hline & $\begin{array}{l}\text { Maximise gains of BoNT-A with } \\
\text { therapy }\end{array}$ & $\begin{array}{l}\text { If there is enough clinical evidence to provide BoNT-A in the first } \\
\text { place then there are gains to be made for the client and these should } \\
\text { be maximised by therapeutic intervention - preferably a combination } \\
\text { of OT and PT to ensure gains are made in muscle length, muscle } \\
\text { strength, movement patterns, splinting is provided and as well as } \\
\text { placing this into functional movement patterns and translated into } \\
\text { task performance }\end{array}$ \\
\hline
\end{tabular}


Table 4: Muscles Injected

\begin{tabular}{|l|l|l|l|}
\hline $\begin{array}{l}\text { Muscle } \\
\text { N=91 responses }\end{array}$ & $\begin{array}{l}\text { Rank of injection } \\
\text { frequency } \\
\text { (lowest=1 to } \\
\text { highest=20) }\end{array}$ & $\begin{array}{l}\text { Never injected } \\
\text { (n of 91) }\end{array}$ & $\begin{array}{l}\text { Don't Know } \\
\text { (n of 91) }\end{array}$ \\
\hline Subscapularis & 1 & 37 & 26 \\
\hline Rhomboids & 1 & 46 & 17 \\
\hline Levator scapulae & 2 & 38 & 27 \\
\hline Teres minor and infraspinatus & 3 & 41 & 17 \\
\hline Extensor Digitorum & 4 & 45 & 15 \\
\hline Extensor carpi radialis longus or brevis & 5 & 43 & 17 \\
\hline Extensor carpi ulnaris & 5 & 44 & 16 \\
\hline Latissimus dorsi & 6 & 38 & 19 \\
\hline Extensor pollicus longus or brevis & 7 & 40 & 15 \\
\hline Supinator & 7 & 33 & 14 \\
\hline Opponens pollicis & 8 & 26 & 17 \\
\hline Teres Major & 8 & 29 & 17 \\
\hline Triceps & 9 & 28 & 9 \\
\hline Abductor pollicus longus & 10 & 26 & 15 \\
\hline Lumbricals & 11 & 21 & 10 \\
\hline Adductor pollicus brevis & 12 & 18 & 14 \\
\hline Pronator quadratus & 13 & 13 & 15 \\
\hline Pronator teres & 14 & 12 & 11 \\
\hline Pectoralis major & 15 & 10 & 3 \\
\hline Flexor pollicis brevis or longus & 16 & 5 & 8 \\
\hline Flexor carpi ulnaris & 17 & 3 & 6 \\
\hline Flexor carpi radialis & 17 & 3 & 7 \\
\hline Brachioradialis & 18 & 2 & 8 \\
\hline Brachialis & 19 & 2 & 8 \\
\hline $\begin{array}{l}\text { Flexor digitorum profundus or } \\
\text { superficialis }\end{array}$ & 19 & 4 & 7 \\
\hline Biceps & 20 & 1 & 3 \\
\hline & & & \\
\hline
\end{tabular}

*If the sum of values was the same for different items, the same rank was used. 
Table 5: Assessment use and perceived relevance

\begin{tabular}{|c|c|c|c|c|c|}
\hline Assessment Name & $\begin{array}{l}\text { Rank of least to } \\
\text { most frequently } \\
\text { used } \\
\text { assessment } \\
\text { Low }=1 \\
\text { High= } 26^{\star} \\
\text { (n=item } \\
\text { respondents) }\end{array}$ & $\begin{array}{l}\text { Rank of least } \\
\text { to most } \\
\text { relevant } \\
\text { assessment } \\
\text { Low }=1 \\
\text { high }=27^{\star} \\
\text { (n=item } \\
\text { respondents) }\end{array}$ & $\begin{array}{l}\text { Therapists who } \\
\text { never use } \\
\text { assessment } \\
\mathrm{n}(\% \text { of } \\
\text { frequency of } \\
\text { use } n=\text { item } \\
\text { respondents ) }\end{array}$ & $\begin{array}{l}\text { Therapists who } \\
\text { have never } \\
\text { heard of } \\
\text { assessment } \\
\mathrm{n} \% \text { of } \\
\text { frequency of } \\
\text { use } n=\text { item } \\
\text { respondents ) }\end{array}$ & $\begin{array}{l}\text { Therapists } \\
\text { unable to judge } \\
\text { relevance of } \\
\text { assessment } \\
n(\% \text { of } \\
\text { relevance rating } \\
n=i t e m \\
\text { respondents) }\end{array}$ \\
\hline Penn Spasm Scale & $1(82)$ & $4(78)$ & $28(34)$ & $53(65.5)$ & $67(86)$ \\
\hline London Handicap Scale & $2(81)$ & $2(80)$ & $26(32)$ & $54(66.5)$ & $69(86)$ \\
\hline $\begin{array}{l}\text { Re-integration to Normal } \\
\text { Living Index }\end{array}$ & $2(82)$ & $6(78)$ & $33(40)$ & $46(56)$ & $65(83)$ \\
\hline Rankin Scale & $3(80)$ & $4(78)$ & $49(61.5)$ & $28(35)$ & $63(81)$ \\
\hline $\begin{array}{l}\text { Warrtenberg Pendulum } \\
\text { Test }\end{array}$ & $3(82)$ & $1(79)$ & $26(32)$ & $54(66)$ & $71(90)$ \\
\hline $\begin{array}{l}\text { Patient Rated Wrist } \\
\text { Evaluation }\end{array}$ & $4(83)$ & $3(77)$ & $32(38.5)$ & $48(58)$ & $66(85.5)$ \\
\hline Wolf Motor Function Test & $5(82)$ & $7(78)$ & $39(47.5)$ & $39(47.5)$ & $60(77)$ \\
\hline ArMA Activity Measure & $5(81)$ & $5(80)$ & $26(32)$ & $51(63)$ & $71(89)$ \\
\hline $\begin{array}{l}\text { Assessment of Motor and } \\
\text { Process Skills (AMPS) }\end{array}$ & $6(78)$ & $9(78)$ & $57(73)$ & $16(20.5)$ & $52(66.5)$ \\
\hline Box and Block & $6(81)$ & $8(78)$ & $43(53)$ & $32(39.5)$ & $56(72)$ \\
\hline Motor Activity Log & $7(81)$ & $10(77)$ & $44(54.5)$ & $29(36)$ & $55(72)$ \\
\hline Spasm Frequency Scale & $8(83)$ & $8(77)$ & $30(36)$ & $44(53)$ & $57(74)$ \\
\hline $\begin{array}{l}\text { Range of Motion- Torque- } \\
\text { Controlled Goniometry }\end{array}$ & $9(82)$ & $12(77)$ & $54(66)$ & $15(1.5)$ & $43(56)$ \\
\hline $\begin{array}{l}\text { Disabilities of the Arm, } \\
\text { Shoulder and Hand } \\
\text { Questionnaire (DASH) }\end{array}$ & $10(80)$ & $11(79)$ & $43(54)$ & $19(24)$ & $52(66)$ \\
\hline Barthel Index & $11(83)$ & $14(78)$ & $60(72)$ & $2(2.5)$ & $22(29)$ \\
\hline Action Research Arm Test & $12(82)$ & $13(79)$ & $39(47.6)$ & $16(19.5 \%)$ & $37(47)$ \\
\hline Purdue Peg Board & $13(83)$ & $15(78)$ & $40(48)$ & $11(13)$ & $32(41)$ \\
\hline Ashworth Scale & $14(83)$ & $16(80)$ & $44(53)$ & $1(1)$ & $25(31.5)$ \\
\hline $\begin{array}{l}\text { Canadian Occupational } \\
\text { Performance Measure }\end{array}$ & $15(83)$ & $19(82)$ & $38(46)$ & $6(7.2)$ & $28(34)$ \\
\hline Nine-Hole Peg Test & $16(82)$ & $18(76)$ & $30(36.5)$ & $5(6)$ & $16(21)$ \\
\hline $\begin{array}{l}\text { Functional Independence } \\
\text { Measure }\end{array}$ & $17(84)$ & $18(80)$ & $41(49)$ & $3(3.5)$ & $10(12.5)$ \\
\hline Goal Attainment Scale & $18(84)$ & $25(80)$ & $24(28.6)$ & $3(3.5)$ & $8(10)$ \\
\hline $\begin{array}{l}\text { Pain Visual Analogue } \\
\text { Scale }\end{array}$ & $19(83)$ & $23(79)$ & $14(17)$ & $5(6)$ & $9(11.5)$ \\
\hline $\begin{array}{l}\text { Motor Assessment } \\
\text { Scale(MAS) or UL MAS }\end{array}$ & $20(86)$ & $20(80)$ & $19(22)$ & $2(2.5)$ & $12(15)$ \\
\hline Modified Tardieu Scale & $21(84)$ & $22(79)$ & $15(18)$ & $8(9.5)$ & $15(19)$ \\
\hline $\begin{array}{l}\text { Manual Muscle test } \\
\text { (muscle strenath rating) }\end{array}$ & $22(84)$ & $21(78)$ & $11(13)$ & $2(2.5)$ & $5(6.5)$ \\
\hline Tardieu Scale & $23(87)$ & $26(79)$ & $26(30)$ & $0(0)$ & $9(11.5)$ \\
\hline Modified Ashworth Scale & $24(85)$ & $24(82)$ & $9(10.5)$ & $1(1)$ & $6(7.5)$ \\
\hline $\begin{array}{l}\text { Range of Motion- } \\
\text { Goniometry }\end{array}$ & $26(88)$ & $27(80)$ & $7(8)$ & $0(0)$ & $4(5)$ \\
\hline
\end{tabular}

*Derived from sum of response values; equal sum scores given equal rank 
Action Research Arm Test: Hsieh CL, Hsueh IP, Chiang FM \& Lin PH. (1998). Inter-rater reliability and validity of the Action Research Arm test in stroke patients. Age \& Ageing 27:107-14.

Arm Activity Measure*: Ashford S, Slade M, Turner-Stokes L. (2013) Conceptualisation and development of the arm activity measure (ArmA) for assessment of activity in the hemiparetic arm. Disability and Rehabilitation. (2013) DOI: 10.3109/09638288.2012.743602

Arm Activity Measure*: Ashford, S. Slade, M. Turner-Stokes, L. (2010) Development of the Arm Activity measure (ArmA) for assessment of activity in the hemiplegic arm. Chartered Society of Physiotherapy Congress. Liverpool, October 15-16.

Ashworth Scale: Ashworth B (1964). Preliminary trial of carisoprodol in multiple sclerosis. Practitioner 192:540-542

Ashworth Scale: Damiano DL, Quinlivan JM, Owen BF, Payne P, Nelson KC, Abel MF (2002). What does the Ashworth Scale really measure and are instrumented measures more valid and precise? Developmental Medicine \& Child Neurology, 44:112-118

Assessment of Motor Processes and Skills : Fisher AG. (1995). Assessment of motor and process skills. Fort Collins (CO): Three Star Press

Barthel Index : Wade DT \& Collin C. (1988). The Barthel ADL Index: A standard measure of physical disability? Disability and Rehabilitation. 10: 64- 67.

Box \& Block Test : Mathiowetz V, Volland G, Kashman N \& Weber K. (1985). Adult norms for the Box and Block Test of manual dexterity. American Journal of Occupational Therapy, 39, 386-391.

Canadian Occupational Performance Measure: Law M, Baptiste S, McColl MA, Opzoomer A, Polatajko H, \& Pollock N. (1990). The Canadian occupational performance measure: an outcome measure for occupational therapy. Canadian Journal of Occupational Therapy, 57: 2 82-87

Disability of the Arm, Shoulder, Hand: Hudak PL, Amadio PC, Bombardier C, Beaton D, Cole D, Davis A, Hawker G, Katz, JN, Makela M, Marx RG, Punnett L, \& Wright J. (1996). Development of an upper extremity outcome measure: The DASH (Disabilities of the Arm, Shoulder, and Head). American Journal of Industrial Medicine, 29: 602-608

Functional Independence Measure : Keith RA, Granger CV, Hamilton BB, \& Sherwin FS. (1987). The functional independence measure: a new tool for rehabilitation. Advances in Clinical Rehabilitation, 1: 6-18.

Goal Attainment Scale : Turner-Stokes L, Williams H, Johnson J.(2009). Goal attainment scaling: does it provide added value as a person-centered measure for evaluation of outcome in neurorehabilitation following acquired brain injury? Journal of Rehabilitation Medicine 41: 528-535

London Handicap Scale : Harwood R, Rogers A, Dickinson E, et al. (1994). Measuring handicap: the London handicap scale, a new outcome measure for chronic disease. Quality in Health Care 3: 11-16.

Manual Muscle Test : Mendell JR, Florence J. (1990). Manual muscle testing. Muscle Nerve, 13 (Suppl): S16-20

Modified Ashworth Scale : Bohannon RW, Smith MB (1987).Interrater reliability of a modified Ashworth scale of muscle spasticity. Physical Therapy 67: 206-207

Modified Tardieu scale : Gracies JM, Marosszeky JE, Renton R, Sandanam J, Gandevia SC,Burke D. (2000) Short-term effects of dynamic lycra splints on upper limbs in hemiplegic patients. Archives of Physical Medicine and Rehabilitation 81: 1547-1555.

Motor Activity Log : van der Lee J, Beckerman H, Knol DL, de Vet HCW, Bouter LM. (2004). Clinimetric properties of the Motor Activity Log for the assessment of arm use in hemiparetic patients. Stroke. 35: 1-5

Motor Activity Log: Taub E, Morris D, Bowman M, Delgado A, Uswatte G. (1996). UpperExtremity Motor Activity Log [Manual]. Available from Edward Taub, Psychology Department, UAB, $\mathrm{CH} 415$, Birmingham, Ala.

Motor Assessment Scale (Upper Limb items): Carr DL J.H, Shepherd R.B, Nordholm L \& Lynne D. (1985). Investigation of a New Motor Assessment Scale for Stroke Patients. Physical Therapy, 65: 175-180. 
Nine-hole Peg Test : Mathiowetz V, Weber K, Kashman N, Volland G. (1985). Adult Norms for the Nine Hole Peg Test of Finger Dexterity. The Occupational Therapy Journal of Research. 5:24-33. Nine-hole Peg Test : Rusmorje, T. (1942). The R-G Pegboard test of finger dexterity. Journal of Psychology, 26: 523-529.

Pain Visual Analogue Scale: Carrison, AM. (1983). Assessment of chronic pain. I. Aspects of the reliability and validity of the visual analogue scale. Pain, 16:187-101

Patient Rated Wrist Evaluation : MacDermid JC, Turgeon T, Richards RS, Beadle M, Roth, JH. (1998). Patient Rating of Wrist Pain and Disability: A Reliable and Valid Measurement Tool. Journal of Orthopaedic Trauma, 12: 577-586

Penn Spasm Frequency Scale: Penn RD, Savoy SM, Corcos D, Latash M, Gottlieb G, Parke B, Kroin JS.(1989). Intrathecal baclofen for severe spinal spasticity. New England Journal of Medicine, 320:1517-1521

Purdue Peg Board: Tiffin J, Asher, EJ. (1948). The Purdue Pegboard: norms and studies of reliability and validity. Journal of Applied Psychology, 32: 234-247

Range of Motion (Goniometry): Berryman, RN \& Bandy, WD. (2002). Joint range of motion and manual muscle testing. Philadelphia: WB Saunders Co.

Range of Motion (Torque controlled): Osternig LR.(1986). Isokinetic dynamometry: implications for muscle testing and rehabilitation. Exercise and Sport Sciences Reviews, 14: 45-80.

Rankin Scale: Banks, JL, Marotta, CA. (2007). Outcomes validity and reliability of the modified Rankin scale: Implications for stroke clinical trials a literature review and synthesis. Stroke, 38: 1091-1096

Reintegration to Normal Living :Wood-Dauphinee SL, Opzoomer MA, Williams JI, Marchand B, Spitzer WO. (1988). Assessment of global function: The Reintegration to Normal Living Index. Archives of Physical Medicine \& Rehabilitation. 69:583-90.

Tardieu Scale: Tardieu G, Shentoub S, Delarue R. (1954). A la recherche d'une technique de mesure de la spasticite. Rev Neurol 91: 143-144

Wolf Motor Function Test: Wolf SL, Catlin PA, Ellis M, Archer AL, Morgan B, Piacentino A. (2001). Assessing wolf motor function test as outcome measure for research in patients after stroke. Stroke, 32:1635-1639. 